\title{
Amendments to the JCHPT Handbook
}

The JCHPT has agreed to extend the duration of approval which may be granted to honorary senior registrars in respect of higher training undertaken in research appointments. These amended regulations replace those published in the JCHPT Handbook (1987) on pages 54 and 55.

(1) Requirements for approval of higher training spent entirely in research posts

Honorary senior registrars who occupy a research post for a minimum of four years will be eligible for recognition of the entire period of higher training if the criteria detailed below are met. Application must be made in advance and must be made on behalf of the trainee by the local Scheme Organiser.

(a) A programme of clinical experience for the whole period of higher training must be specified. There should be at least four weekly sessions of clinical work in psychiatry, apart from the research work; three sessions weekly of clinical work may be accepted at the discretion of the JCHPT. There should be a rotational experience, providing a variety of training settings including, where possible, experience in a general hospital. The names of consultant supervisors should be given. The programme should be tailored to the individual trainee's needs, allowing gaps in previous experience to be remedied as well as providing further general and special clinical experience.

(b) Trainees must receive academic supervision. The Senior Registrar Tutor should act as Tutor to such trainees and regularly review their progress. A separate research supervisor should be identified.

(c) Trainees should have opportunities to gain experience in administration, such as serving on local committees.

(d) Trainees should undertake teaching of junior psychiatrists or medical students. (e) The trainee should attend academic and peer group meetings along with senior registrars on the local scheme.

(f) The trainee should undertake senior emergency duties.

(2) Requirements for approval of more than one year and up to three years higher training gained in a research post

Honorary senior registrars who occupy a research post for more than one year and up to three years may apply to the JCHPT for recognition of higher training experience for this period. The criteria detailed above will be applied to such applications with the exceptions that the number of clinical sessions required will be less, and the requirements to undertake teaching and administration will not apply. Depending on the nature of the research project the JCHPT may accept that only two clinical sessions are spent in work unrelated to the project.

A trainee who has spent three years in such a post cannot be considered sufficiently trained for consultant appointment until at least one year has also been spent in a full-time senior registrar or honorary senior registrar/lecturer post.

(3) Approval of one year spent in a research post Higher trainees may spend one year of the four year training period in full-time research of any nature.

(4) Recognition of research experience gained by post-membership registrars

Post-membership Registrars undertaking research are eligible for recognition of up to two year's experience under the conditions detailed under (2) and (3) above. Recognition is not effective until subsequent appointment to a substantive senior registrar or honorary senior registrar/lecturer post.

\section{A statement on attendance of Health Authority staff at Consultants' Advisory Appointments Committees}

This statement appeared in the February edition of the Psychiatric Bulletin and confirmed that Health Authority Staff could only attend Consultants' Advisory Appointment Committees if it was the wish of the majority of members of the Committee.

The procedure is different in Scotland in that
Scottish Regulations do allow a Health Board Officer to attend meetings of an Advisory Appointments Committee and to contribute at the discretion of the Chairman.

Dr J. L. T. BIRLEY President 